\title{
Lean Implementation - Lead by Example
}

\author{
Heidi Pschibilla \\ München, Germany \\ HeidiPschibilla@gmx.net
}

\begin{abstract}
Successful Lean Transformation achieved through leading by example. It has been noted that the number one secret to success for a successful and sustainably lean transformation is management commitment and support the initiative. This presentation is targeted towards identifying those key elements that management must possess and exhibit in order to support the initiative and drive the right culture change. Heidi's presentation is based on a real case in a European manufacturing company.
\end{abstract}

